J. Dairy Sci. 92:1512-1519

doi:10.3168/jds.2008-1578

(c) American Dairy Science Association, 2009.

\title{
Effects of local anesthetic and a nonsteroidal antiinflammatory drug on pain responses of dairy calves to hot-iron dehorning
}

\author{
M. Stewart, ${ }^{* 1}$ J. M. Stookey,† K. J. Stafford,‡ C. B. Tucker,§ A. R. Rogers, ${ }^{*}$ S. K. Dowling, ${ }^{*}$ G. A. Verkerk,\# \\ A. L. Schaefer, $\|$ and J. R. Webster* \\ ${ }^{*}$ AgResearch Ltd, Private Bag 3123, Hamilton 3240, New Zealand \\ †University of Saskatchewan, Saskatoon, Saskatchewan, Canada S7N 5B4 \\ ¥Massey University, Private Bag 11222, Palmerston North 4442, New Zealand \\ §University of California, Davis 95616 \\ \#DairyNZ, Private Bag 3221, Hamilton 3240, New Zealand \\ \|Agri-Food Canada, Lacombe Research Centre, Lacombe, Alberta, Canada T4L 1W1
}

\section{ABSTRACT}

This study examined the effects of a nonsteroidal antiinflammatory agent (NSAID) on physiological responses of calves immediately after hot-iron dehorning $(\mathrm{DH})$ and during the time that local anesthetic (LA) wears off ( 2 to $3 \mathrm{~h}$ ) after this procedure. Forty-six calves (33 $\pm 0.3 \mathrm{~d}$ of age) were randomly assigned to 6 treatments: hot-iron $\mathrm{DH}$ versus sham $\mathrm{DH}$ with either no pain mitigation, LA alone, or LA with NSAID (i.v. Meloxicam). Eye temperature (measured using infrared thermography) was recorded every $5 \mathrm{~min}$ for $3 \mathrm{~h}$ after treatments. Heart rate (HR) and heart rate variability (HRV) were recorded continuously; for analysis of HRV, short segments of 512 interbeat intervals were examined. After DH without LA or NSAID, HR increased by $35 \pm$ 3.0 beats $/ \mathrm{min}$ in the first $5 \mathrm{~min}$ and remained elevated above baseline for $3 \mathrm{~h}$. The HRV around the time of DH did not differ between treatments; however, the root mean square of successive differences decreased from 68 to $41 \pm 12.6 \mathrm{~ms}$ immediately following $\mathrm{DH}$ without pain relief, suggesting a decrease in vagal tone at this time. Between 2 and $3 \mathrm{~h}$ following $\mathrm{DH}$ with LA, there was a decrease in eye temperature $\left(-0.6 \pm 0.1^{\circ} \mathrm{C}\right)$, an increase in $\mathrm{HR}(8 \pm 3.0$ beats per min) and changes in HRV. Changes in HRV at this time included a decreased high-frequency power and an increase in the low-frequency power and low-frequency/high-frequency ratio, indicating a change in sympatho-vagal balance. The changes in eye temperature, HR, and HRV between 2 and $3 \mathrm{~h}$ following DH with LA indicated the onset of pain coinciding with the time that the LA effects wear off. In addition, this study demonstrated that the

Received July 24, 2008.

Accepted November 21, 2008.

${ }^{1}$ Corresponding author: mairi.stewart@agresearch.co.nz combination of LA and NSAID mitigated the onset of pain responses when the LA wanes.

Key words: dairy calf, hot-iron dehorning, local anesthetic, analgesia

\section{INTRODUCTION}

Hot-iron dehorning (DH) is a routine husbandry practice performed on calves, typically between 2 to 6 wk of age, which prevents horn development by removing the horn buds using heat cauterization. This procedure should be done at an early age, because after the horn bud develops and becomes fixed to the skull, amputation DH is necessary (Weaver et al., 2005) and this is considered more painful than hot-iron DH (Stafford and Mellor, 2005). The purpose of both practices is to minimize the risk of injuries to stockpersons and other animals, the latter contributing to carcass downgrading through bruising and hide damage. Despite evidence that demonstrated the benefits of using analgesics, it is common practice and permitted to dehorn calves without local anesthetic (LA) in some countries.

Use of LA can reduce behaviors indicative of acute pain during hot-iron $\mathrm{DH}$ (e.g., tail flicking, rearing, escape behavior) and other behaviors indicative of post-DH pain, such as head shaking and ear flicking (Stafford and Mellor, 2005). There is disagreement about the time course of pain associated with hot-iron DH and the controversy likely hinges on the different measures chosen to assess pain. Cortisol concentrations generally return to baseline levels approximately 1 to $2 \mathrm{~h}$ after hot-iron DH without LA (Petrie et al., 1996; Graf and Senn, 1999; Grøndahl-Nielsen et al., 1999), although one group found elevated cortisol levels $24 \mathrm{~h}$ after the procedure (Morisse et al., 1995). Nevertheless, other studies showed that the pain associated with hotiron $\mathrm{DH}$ lasts longer than $3 \mathrm{~h}$. For example, following hot-iron DH without LA, pain-related behaviors (e.g., head shaking) lasted for $2 \mathrm{~h}$ (Graf and Senn, 1999) 
and heart rate (HR) remained high for up to $3.5 \mathrm{~h}$ (Grøndahl-Nielsen et al., 1999). Furthermore, the use of LA alone may be unsatisfactory for pain alleviation following DH procedures. Lignocaine, the most commonly used LA, is only effective for approximately 2 to $3 \mathrm{~h}$ after administration, after which pain-related behaviors, cortisol concentrations, and inflammationrelated pain increase (Stafford and Mellor, 2005).

Studies investigating the pain associated with amputation $\mathrm{DH}$ have shown that a combination of LA and a nonsteroidal antiinflammatory drug (NSAID) was required to alleviate both the acute pain and the longer term pain experienced after DH (Stafford and Mellor, 2005). Although studies investigated the benefits of using a combination of LA and NSAID following amputation DH (Stafford and Mellor, 2005), less information is available regarding the use of a combination of LA and NSAID during hot-iron DH. Faulkner and Weary (2000) measured pain-related behaviors between 3 and $24 \mathrm{~h}$ after hot-iron DH of sedated animals (with xylazine) also given a LA and an NSAID (ketoprofen), and found that the calves given NSAID had reduced ear flicking for up to $24 \mathrm{~h}$ and head shaking for up to $12 \mathrm{~h}$, indicating that pain continues well beyond the established peaks in cortisol.

Recently, it was suggested that a combination of eye temperature, measured by infrared thermography, and heart rate variability (HRV) responses may be useful, noninvasive measures of autonomic nervous system (ANS) activity and thus, pain detection in cattle (Stewart, 2008). Normal cardiac function was characterized by irregular intervals between consecutive beats (interbeat intervals, IBI). The control of the intervals between consecutive beats (HRV) is governed by vagal (increased HRV) and sympathetic (decreased HRV) regulation and HRV provides a more detailed interpretation of cardiac activity in terms of ANS activity than HR alone (Malik and Camm, 1995). Indeed, the balance between sympathetic and parasympathetic activity can provide an insight into how an animal perceives a situation. For example, Sleigh and Henderson (1995) found a reduction in the relative intensity of the highfrequency (HF) power (an HRV measure of vagal tone) in presurgical patients and this reduction positively correlated with perceived anxiety levels before surgery. There was no relationship between anxiety levels and HR alone. Heart rate variability has been used to assess ANS regulation of cardiovascular function in human and veterinary medicine, and although there is precedent to use HRV to assess stress in farm animals (von Borell et al., 2007), relatively few studies have investigated HRV in response to painful husbandry procedures.

The aim of this study was to use cardiac responses to evaluate the immediate response to hot-iron $\mathrm{DH}$ and to evaluate the effects of using an NSAID to alleviate the pain associated with the LA wearing off after this procedure. The predictions were 2-fold: 1 ) that pain relief using LA would reduce the immediate responses to $\mathrm{DH}$, and 2) that administration of an NSAID before hot-iron DH would eliminate pain responses when the effects of LA wear off.

\section{MATERIALS AND METHODS}

The protocol and conduct of this study were approved by the Ruakura Animal Ethics Committee, Hamilton, New Zealand. The inclusion of animals dehorned without pain relief was recognized as critical to the design and interpretation of the experiment; however, the animals exposed to this treatment were kept to a minimum ( $\mathrm{n}=6$, rather than $\mathrm{n}=8$ as in other treatments).

\section{Animals}

Forty-six Holstein-Friesian, mixed-sex calves (23 heifers and 23 bulls), average age $33 \pm 0.3 \mathrm{~d}$ (range 30 to $39 \mathrm{~d}$ ), mean $\mathrm{BW}$ of $53 \pm 0.8 \mathrm{~kg}$ (range 42 to 65 $\mathrm{kg}$ ) were used. Calves were group housed in an indoor calf-rearing facility on straw bedding. Calves were fed 2 $\mathrm{L}$ of milk replacer twice daily and provided with grain (Gusto Calf Blend 16, Allied Grain Co-operative Ltd., Te Awamutu, New Zealand) and water ad libitum.

\section{Treatments and Procedure}

Calves were randomly assigned to 1 of 6 treatments: hot-iron $\mathrm{DH}$ versus sham $\mathrm{DH}$ with no pain mitigation, LA alone, or LA with NSAID. Treatments were as follows: 1) Control $(\mathrm{n}=8)$ : saline injected $(5 \mathrm{~mL})$ around each cornual nerve and horn bud area handled to simulate DH 10 min later (cold cautery iron held against each horn bud); 2) hot-iron $\mathrm{DH}(\mathrm{DH} ; \mathrm{n}=6)$ : saline injected $(5 \mathrm{~mL})$ around each cornual nerve and horn buds removed with a standard gas-powered cautery iron (ABER LPG debudder, Shoof International Ltd., Cambridge, New Zealand) $10 \mathrm{~min}$ after saline injection; 3) LA and DH (LA+DH; $\mathrm{n}=8)$, LA ( $5 \mathrm{~mL}$ of $2 \%$ lignocaine hydrochloride, Lopaine, Ethical Agents Ltd., Auckland, New Zealand) administered by injection around each cornual nerve, then 3 to $4 \mathrm{~mL}$ infiltrated s.c. around the base of each horn bud (Weaver et al., 2005), and buds removed with a cautery iron 10 min after last LA injection; 4) LA control (LA; $\mathrm{n}=$ 8): LA administered as above $10 \mathrm{~min}$ before horn bud handled to simulate hot-iron DH; 5) LA and NSAID control (LA+NSAID; $\mathrm{n}=8$ ): meloxicam (Metacam, Boehringer Ingelheim Ltd., Auckland, New Zealand; half-life of approximately $26 \mathrm{~h}$ in cattle), a preferential 
COX-2 inhibiting NSAID, injected i.v. $(0.5 \mathrm{mg} / \mathrm{kg}$ BW into jugular vein) $30 \mathrm{~min}$ before the start of sampling (55 min before DH), LA administered as above (to both caudal nerve and horn buds) 10 min before horn bud handled to simulate DH; 6) LA, NSAID, and DH $(\mathrm{LA}+\mathrm{NSAID}+\mathrm{DH} ; \mathrm{n}=8)$ : Metacam and LA were administered as above and buds removed 10 min later with cautery iron. Treatments were balanced for sex, randomized and balanced across test days, and were carried out by the same operator.

Four calves were treated each day. The day before treatment, each calf acted as a companion animal for the calf undergoing treatment that day to habituate them to the treatment area. Thus, companion calves were of a similar age and a new companion calf was randomly assigned to each individual. On this training day, each calf had its coat clipped down the left side of the body to improve contact for the HR electrodes, and calves were given time to habituate to wearing HR equipment (1 h, S810i, Polar Electro Oy, Kempele, Finland) and to restraint in a calf head catch (20 min, Cattlemaster, Te Pari Products, Oamaru, New Zealand). The hair on the necks was clipped to facilitate jugular vein injections. On treatment days, each of the 4 calves and its companion calf were confined as pairs within 4 holding pens $(2.3 \times 2.5 \mathrm{~m})$ on straw bedding with access to grain and water. Thirty minutes before the start of sampling, each calf was fitted with a HR monitor and injected i.v. with either NSAID or saline. After $30 \mathrm{~min}$, the calf was moved from its holding pen and restrained in the head catch for $15 \mathrm{~min}$ of baseline data collection, followed by a cornual nerve injection of LA or saline (average injection time of $53 \pm 2 \mathrm{~s}$ ), then $517 \pm 16 \mathrm{~s}$ for the LA to take effect. This was followed by a prick test to verify the success of the cornual nerve block before proceeding with administration of a local infiltrate around each horn bud or a sham infiltrate (no needle) for saline-treated calves (average time taken $528 \pm 10 \mathrm{~s}$ ), then $526 \pm 20 \mathrm{~s}$ before the $\mathrm{DH}$ or sham procedure was administered (average time taken $131 \pm 4 \mathrm{~s}$ ). The recommended minimum amount of time between injecting LA and hot-iron DH was 3 min (NZVA, 2000); therefore, this timeline was considered enough time for the LA to be effective. A second prick test was performed before proceeding with $\mathrm{DH}$. The infiltrate was always successful and no further LA or waiting time was ever required. Calves were released back into the holding pen with their companion $15 \mathrm{~min}$ after DH or sham DH where cardiac responses were recorded continuously and maximum eye temperature was recorded at $5 \mathrm{~min}$ intervals for $3 \mathrm{~h}$ while calves were unrestrained.

\section{Infrared Thermography}

An infrared thermography camera (ThermaCam S60, FLIR Systems AB, Danderyd, Sweden) was used to collect images of the eye. The maximum temperature $\left({ }^{\circ} \mathrm{C}\right)$ within the area of the medial posterior palpebral border of the lower eyelid and the lacrimal caruncle (Stewart et al., 2008) was recorded immediately into an Excel spreadsheet (Microsoft, Redmond, WA) every $5 \mathrm{~min}$ (one image per 5 -min period) in the holding pens for 3 $\mathrm{h}$ after DH. All images were taken from the same side (left), angle $\left(90^{\circ}\right)$, and distance (approx $0.5 \mathrm{~m}$ ). Ambient temperature $\left({ }^{\circ} \mathrm{C}\right)$ and relative humidity (\%) inside the sampling area were recorded with a weather meter (Kestrel 4000, Nielsen-Kellerman, Boothwyn, PA) and entered into the infrared camera to calibrate it for atmospheric conditions.

\section{Heart Rate and Heart Rate Variability}

Continuous IBI were recorded using the Polar HR monitors. Ultrasound transmission gel was applied liberally to the clipped site at each electrode contact point to improve conductivity. The electrodes and transmitter were built into an elastic strap, provided with the Polar HR monitor, which was strapped firmly around the chest, immediately behind the forelimbs, with the HR monitor attached. At the end of each sampling period, the stored IBI data were downloaded for analysis. Timedomain measures included mean HR (beats/min) and root mean square of successive differences (RMSSD), and frequency-domain traits included the HF (0.30 to $0.80 \mathrm{~Hz})$ and the $\mathrm{LF}(0.04$ to $0.30 \mathrm{~Hz})$ powers and the $\mathrm{LF} / \mathrm{HF}$ ratio which were calculated with fast Fourier transform (FFT) using HRV software (Niskanen et al., 2004). Short segments of data containing 512 beats (IBI pools) were examined at 2 time points: around the time of DH (2 IBI pools before DH and 2 after) and 12 IBI pools representing the 2 to $3 \mathrm{~h}$ after $\mathrm{DH}$ to fulfill recommendations for analysis of HRV using FFT made by the Task Force of the European Society of Cardiology and the North American Society of Pacing and Electrophysiology (1996) and von Borell et al. (2007). In addition, frequency bandwidths were selected to take into consideration the respiratory rate of calves. Thus, the HF and LF power were presented as normalized units (nu) to account for interindividual differences. Normalized units represent the relative value of each power component in proportion to the total power minus the very low frequency component (frequencies lower than the lower limit of the LF band). Continuous recordings of IBI data were prone to measurement 
Table 1. Change in maximum eye temperature $\left({ }^{\circ} \mathrm{C}\right) \pm \mathrm{SEM}$ between 2 and $3 \mathrm{~h}$ after treatment

\begin{tabular}{lcccccc}
\hline & \multicolumn{4}{c}{ Treatment $^{1}$} \\
\cline { 2 - 6 } Item & Control & DH & LA & LA+DH & LA+NSAID & LA+NSAID+DH \\
\hline Calves, n & 8 & 6 & 8 & 8 & 7 \\
2 to 2.5 h after dehorning & $37.8 \pm 0.1$ & $37.9 \pm 0.1$ & $37.9 \pm 0.1$ & $38.1 \pm 0.1$ & $37.9 \pm 0.1$ & $37.8 \pm 0.1$ \\
2.5 to 3 h after dehorning & $37.6 \pm 0.1$ & $38.0 \pm 0.1$ & $37.9 \pm 0.1$ & $37.5 \pm 0.1$ & $37.8 \pm 0.1$ & $37.8 \pm 0.1$ \\
Difference & $-0.2 \pm 0.1$ & $0.0 \pm 0.1$ & $0.0 \pm 0.1$ & $-0.6 \pm 0.1^{*}$ & $-0.1 \pm 0.1$ & $-0.0 \pm 0.1$ \\
\hline
\end{tabular}

${ }^{1} \mathrm{DH}=$ dehorned without local anesthetic; $\mathrm{LA}=$ local anesthetic control; LA+DH = dehorned with local anesthetic; LA+NSAID $=$ local anesthetic and nonsteroidal antiinflammatory drug control; LA+NSAID + DH $=$ dehorned with local anesthetic and NSAID.

$* P<0.001$.

errors (Marchant-Forde et al., 2004); therefore, before analysis, a correction function within the Polar software (Polar Precision Performance Software, version 4.03; Polar Electro, Oy), set on default parameters, was used to correct for any artifacts (e.g., to eliminate ectopic heartbeats). Only data sets with an error rate of $<5 \%$ were included in the analysis. Only 10 individual IBI pools were removed because of this type of error, and these deletions were evenly distributed throughout the treatments. Interbeat interval pools were labeled from -2 to -1 (before $\mathrm{DH}$ ), 1 to 2 (immediately after $\mathrm{DH}$ ), and 24 to 35 ( 2 to $3 \mathrm{~h}$ after $\mathrm{DH}$, to the end of the 3 -h period). The IBI pool labeled 1 included the DH procedure.

\section{Statistical Analysis}

An ANOVA was used to analyze the immediate effect of $\mathrm{DH}$ on $\mathrm{HR}$ to test for overall treatment differences before (25 to 15 min before $\mathrm{DH}$ ), 5 min after $\mathrm{DH}$, and the difference between these values. When this ANOVA detected a trend in overall differences in the change before and after DH $(P \leq 0.10)$, between treatments, contrasts were used to compare the change in HR from 0 for each treatment. To evaluate the effect of the LA wearing off, changes in eye temperature and HR between 2 to $3 \mathrm{~h}$ were calculated from the average 30 min before and $30 \mathrm{~min}$ after $2.5 \mathrm{~h}$ post-DH. The 2 - to 3 -h period was chosen based on previous findings that suggested the effectiveness of LA diminished around this time period (Stafford and Mellor, 2005). A 1-way ANOVA was used to compare overall treatment differences before and after $2.5 \mathrm{~h}$, as well as the change at this time. When this ANOVA detected a trend in overall differences in the change before and after $2.5 \mathrm{~h}$ $(P \leq 0.10)$ between treatments, contrasts were used to compare the change in eye temperature and HR from 0 for each treatment. Eye temperature recordings for one calf in the LA+NSAID+DH group were lost because of technical failure.
An ANOVA was used to test for overall treatment differences to analyze the immediate effect of $\mathrm{DH}$ on HRV in 5 values: each of the 4 IBI pools $(-2,-1,1,2)$, and the difference before (IBI pool -1 ) and after (IBI pool 2) DH. An ANOVA was used to test for overall treatment differences separately for each of 12 IBI pools (numbered 24 to 35) to analyze the effects of LA wearing off on HRV parameters (between 2.0 to $2.5 \mathrm{~h}$ vs. 2.5 to $3 \mathrm{~h}$ ). Finally, as with eye temperature and HR, contrasts were used to compare the change in HRV (averages before and after $2.5 \mathrm{~h}$ ) to 0 for each treatment. A natural log-transformation was used before analysis of the frequency domain variables of HRV (HF, LF and $\mathrm{LF} / \mathrm{HF}$ ratio), and for these transformed variables the ratio of change $[\ln$ (before/after)] was used in the place of difference in the analyses described above.

\section{RESULTS}

\section{Eye Temperature}

There were no overall treatment differences in eye temperature at 2.0 to $2.5 \mathrm{~h}\left(37.9 \pm 0.1^{\circ} \mathrm{C}\right.$, mean \pm SEM, $P=0.378)$ or at 2.5 to $3.0 \mathrm{~h}\left(37.8 \pm 0.1^{\circ} \mathrm{C}, P=\right.$ $0.108)$. There were differences between treatments $(P=$ 0.011 ) in the change in eye temperature between 2 and $3 \mathrm{~h}(P=0.011)$; eye temperature decreased by $0.6 \pm$ $0.1^{\circ} \mathrm{C}$ during this time $(P<0.001)$ following $\mathrm{DH}$ with LA (Table 1). There were no significant differences in eye temperature between 2 and $3 \mathrm{~h}$ after $\mathrm{DH}$ for any other treatments $(P \geq 0.129)$.

\section{Heart Rate and Heart Rate Variability}

There were no initial differences in HR between treatment groups before DH (Figure $1 ; P=0.707$ ). In the 5 min after DH there were overall differences between treatments $(P<0.001)$. Specifically, during the first 5 min after $\mathrm{DH}, \mathrm{HR}$ increased in the $\mathrm{DH}$ group by 35 \pm 3.0 beats per minute (bpm; $P<0.001)$ and then 


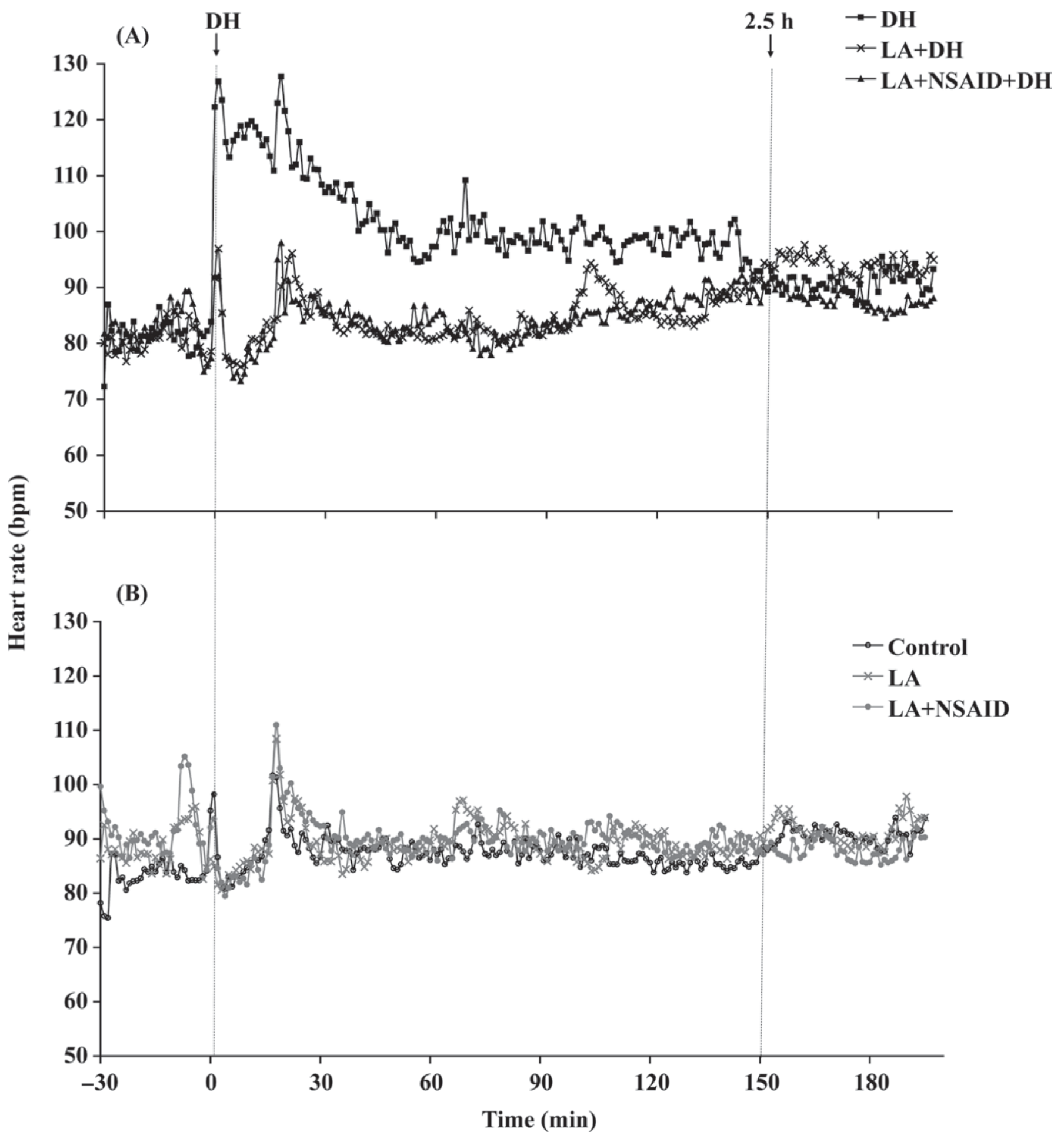

Figure 1. Heart rates for calves in response to treatment: $(\mathrm{A})$ dehorned without local anesthetic $(\mathrm{DH}, \mathrm{n}=6)$, dehorned with local anesthetic $(\mathrm{LA}+\mathrm{DH}, \mathrm{n}=8)$, and dehorned with local anesthetic and nonsteroidal antiinflammatory drug $(\mathrm{LA}+\mathrm{NSAID}+\mathrm{DH}, \mathrm{n}=8) ;$ and $(\mathrm{B})$ control $(\mathrm{n}=$ 8), local anesthetic control (LA, $\mathrm{n}=8$ ), and local anesthetic and NSAID control (LA+NSAID, n 8). 


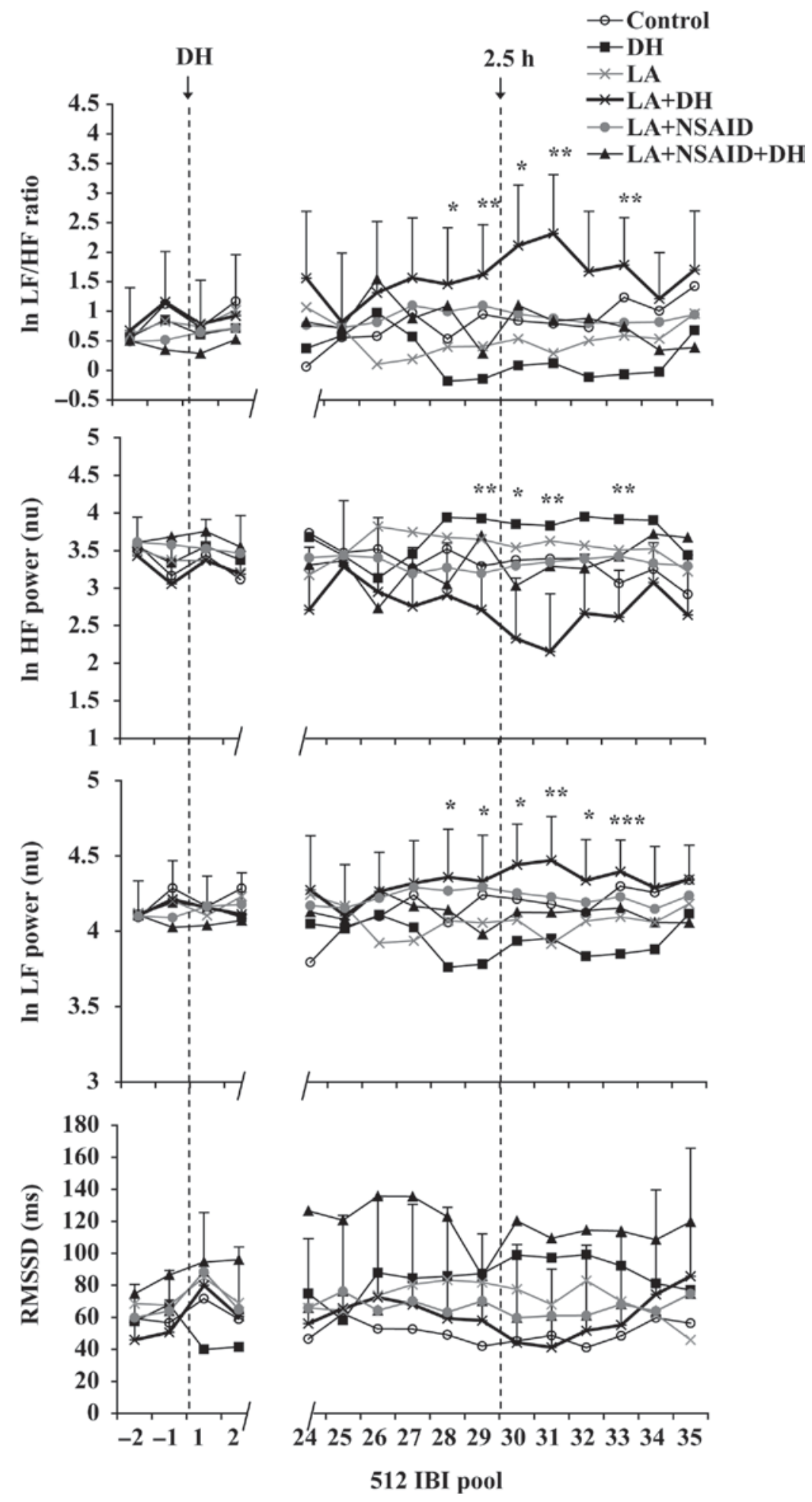

Figure 2. Time domain (root mean square of successive R-R interval differences, RMSSD) and frequency domain [high-frequency (HFnu) and low-frequency (LFnu) power and LF/HF ratio] analysis of 512 interbeat intervals ( \pm SEM) in response to the following treatments (symbols shown in figure legend): control $(\mathrm{n}=8)$, dehorned without local anesthetic $(\mathrm{DH}, \mathrm{n}=6)$, dehorned with local anesthetic $(\mathrm{LA}+\mathrm{DH}, \mathrm{n}=8)$, local anesthetic control (LA, $\mathrm{n}=8$ ), local anesthetic and nonsteroidal antiinflammatory drug control (LA+NSAID, $\mathrm{n}=8$ ), and dehorned with local anesthetic and NSAID (LA+NSAID $+\mathrm{DH}, \mathrm{n}=8$ ). Two time periods are shown. Before DH (IBI pools -2 and -1 ), immediately after DH (IBI pools 1 and 2) and between 2 and $3 \mathrm{~h}$ after DH (IBI pools 24 to 35). The LA was expected to wane during this time. Frequency-domain parameters (HF, LF, HF /LF ratio) are presented as the natural $\log$-transformed data. Statistical significances: ${ }^{*} P<0.05,{ }^{* *} P<0.01$ and $* * * P$ $<0.001$. 
stayed elevated above baseline for the remainder of the 3-h sampling period (Figure 1A). There was a slight change in HR for the other groups in the 5 min after $\mathrm{DH}$ (e.g., increase of $5 \pm 2.4 \mathrm{bpm}$ in the control group, $P=0.063)$.

There were no treatment differences in $\mathrm{HR}$ at 2.0 to $2.5 \mathrm{~h}(93 \pm 4.9 \mathrm{bpm}, P=0.190)$ or at 2.5 to $3.0 \mathrm{~h}(94$ $\pm 5.3 \mathrm{bpm}, P=0.140)$. There were differences in the change between these 2 time periods $(P=0.049)$ : HR increased by $8 \pm 3.0 \mathrm{bpm}(P=0.013)$ for the $\mathrm{LA}+\mathrm{DH}$ group (2.0 to $2.5 \mathrm{~h}: 98 \pm 4.8 \mathrm{bpm}$ vs. 2.5 to $3.0 \mathrm{~h}: 106$ $\pm 5.2 \mathrm{bpm})$. No other treatments showed significant changes in HR between 2 to $3 \mathrm{~h}$ (Figure $1 \mathrm{~A}$ and $\mathrm{B} ; P$ $\geq 0.073)$.

In the 4 IBI pools (approximately $20 \mathrm{~min}$ ) around DH there were no treatment differences in HRV (Figure $2 ; P \geq 0.308)$. Similarly, there were no treatment differences associated with DH ( -1 vs. 2 IBI pool; for frequency domain variables, $P \geq 0.879$ or RMSSD, $P$ $=0.106)$. The only change was that RMSSD in the DH treatment decreased by $27 \mathrm{~ms}$ ( 68 to $41 \mathrm{~ms}$ in -1 and 2 IBI pool, respectively, SEM: $12.6 \mathrm{~ms}, P=0.008)$.

Two to three hours after DH, the HF power was lower at the 29th, 30th, 31st, and 33rd IBI pools ( $P$ $\leq 0.017$ ) and the $\mathrm{LF} / \mathrm{HF}$ ratio was higher at the $28 \mathrm{th}$, 29 th, 30th, 31st, and 33rd IBI pools $(P \leq 0.036)$ in the $\mathrm{LA}+\mathrm{DH}$ group (Figure 2). In addition, the LF power differed between treatments $(P \leq 0.042)$ from the 28 th to the 33rd IBI pool and this difference appears to be caused primarily by LA $+\mathrm{DH}$. There were no differences in RMSSD between treatments $(P \geq 0.060)$. The average change (average of IBI pools 24 to 29 vs. 30 to 35 ) was not different for any variable $(P \geq 0.339)$.

\section{DISCUSSION}

The results support the hypothesis that administration of an NSAID abolishes the pain responses caused when the effects of LA wane between 2 to $3 \mathrm{~h}$ after hot-iron DH as determined by changes in the eye temperature and cardiac responses following the procedure. The drop in eye temperature between 2.5 to $3 \mathrm{~h}$ following DH with LA was similar to the drop reported by Stewart et al. (2008) immediately following hot-iron $\mathrm{DH}$ without LA. Calves DH with LA in the present study had an increase in HR except when they had received an NSAID. This suggests that there was an onset of pain during this time, which was most likely caused by the effects of the LA waning. These results are consistent with studies investigating the effect of administering NSAID on cortisol secretion during amputation DH (Stafford and Mellor, 2005) and behavioral responses to DH (McMeekan et al., 1999; Faulkner and Weary, 2000).
The present study demonstrated that eye temperature not only drops in response to acute/immediate pain $\left(-0.3^{\circ} \mathrm{C}\right.$; Stewart et al., 2008), but also to the onset of pain after 2 to $3 \mathrm{~h}\left(-0.6^{\circ} \mathrm{C}\right)$. Other studies showed changes in behavior at this time. For example, Graf and Senn (1999) found increased head shaking in the third hour after hot-iron DH in calves that had received LA. In the current study, neither the control group nor the group treated with both LA and NSAID had such a drop in eye temperature, suggesting that this response was associated with the onset of pain. The drop in eye temperature is thought to be caused by sympathetically mediated vasoconstriction in response to the pain induced by hot-iron DH (Stewart et al., 2008).

In the present study, the immediate increase in $\mathrm{HR}$ following DH without LA was similar to that in other studies (Schwartzkopf-Genswein et al., 2005; Stewart et al., 2008), but was lower than in other work (approximately $70 \mathrm{bpm}$ in Grøndahl-Nielsen et al., 1999). The prolonged response in HR over $3 \mathrm{~h}$ after $\mathrm{DH}$ was consistent with the study by Grøndahl-Nielsen et al. (1999), who found that HR was elevated for $3.5 \mathrm{~h}$ after hot-iron DH without LA, even when cortisol concentrations had declined after $1 \mathrm{~h}$. This suggests that cortisol responses to DH may be a consequence of the immediate noxious stimulus rather than representing the ongoing pain experienced. These differences between measures highlight the benefit of measuring multiple parameters over extended periods to assess the painful consequences of a noxious procedure. Indeed, HR increased 2 to $3 \mathrm{~h}$ after DH when the LA wore off, although the magnitude of this change $(8 \mathrm{bpm})$ was smaller than the acute response to $\mathrm{DH}$.

Cardiac responses immediately after hot-iron $\mathrm{DH}$ were analyzed using HRV parameters. The RMSSD decreased immediately after DH without LA $(68 \mathrm{~ms}$ before, $42 \mathrm{~ms}$ after $\mathrm{DH}$ ), suggesting a reduction in vagal tone at this time. The magnitude of this change was similar to our previous study ( $67 \mathrm{~ms}$ before, $41 \mathrm{~ms}$ after $\mathrm{DH})$, although there was no difference in Stewart et al. (2008). In the current study, there were no other significant changes in the frequency-domain parameters associated with the procedure. These findings are not consistent with Stewart et al. (2008), in which the HF power decreased and the LF power and the LF/HF ratio increased from baseline 5 min following hot-iron DH without LA. There were several differences in methodology between the current study and Stewart et al. (2008) that may help explain these differences. For example, the analyses of the acute response were performed on a fixed number of beats ( 512 beats) in this study, as opposed to Stewart et al. (2008), which analyzed this over a fixed time period ( $5 \mathrm{~min}$ ). This highlights how data handling decisions may play an 
important role in the outcome and interpretation of HRV information. In relation to the present study, the effects of different drugs and respiration rate on HRV are particularly important. Indeed, there were marked differences in baseline levels between laboratories using different editing software to calculate HRV in calves. Our baseline level of HF power was $36 \mathrm{nu}$; higher than baseline values reported by Mohr et al., (2002; $10 \mathrm{nu})$. A European Working Group (COST action 846; von Borell et al., 2007) was an important step forward in providing a unified approach to this problem.

Despite the modest changes in HRV immediately after the DH procedure, the changes in HRV 2 to $3 \mathrm{~h}$ after DH were consistent with the onset of pain at this time. The calves that were DH with LA had a lower HF power than other treatment groups indicating a reduction in vagal tone, with a higher LF power and $\mathrm{LF} / \mathrm{HF}$ ratio, reflecting a change in the sympatho-vagal balance (von Borell et al., 2007), possibly in the direction of increased sympathetic activity. For example, in the IBI pools with significant differences, HF power for $\mathrm{LA}+\mathrm{DH}$ was half (back-transformed values: $15 \mathrm{nu}$ ) that of $\mathrm{LA}+\mathrm{DH}^{+} \mathrm{NSAID}(37 \mathrm{nu})$. The magnitude of the differences was similar to the change before and after DH without pain relief previously reported (36 before, 16 after DH; Stewart et al., 2008). Thus, the change in ANS activity in the current study may indicate the onset of pain as the effects of the LA wane. High-frequency power decreased in response to automatic milking systems with partially forced traffic $(6 \mathrm{nu}$ in automatic milking systems, $11 \mathrm{nu}$ in normal milking; Hagen et al., $2005)$ and insect harassment and diarrhea in calves (10, 3, $2 \mathrm{nu}$ for baseline, insect harassment, and diarrhea, respectively; Mohr et al., 2002). Both magnitudes of decrease were less marked in these studies compared with the work in our group, highlighting the intricacies of measuring HRV described above.

In conclusion, an NSAID successfully mitigated physiological responses between 2 and $3 \mathrm{~h}$ after hotiron $\mathrm{DH}$ when the pain-relieving effects of LA normally diminish. The present study used several physiological responses to support the view that a combination of LA and NSAID was more effective at alleviating the pain caused by hot-iron DH than LA alone. In addition, this study highlighted the need to improve our understanding of the underlying mechanisms of HRV responses and how these may be used to understand the experiences of pain, fear, and stress in farm animals.

\section{ACKNOWLEDGMENTS}

The authors thank AgResearch staff Gemma Worth for valuable technical assistance and Neil Cox for assistance with statistical analysis and the farm staff at the Tokanui AgResearch farm for taking care of the animals.

\section{REFERENCES}

Faulkner, P. M., and D. M. Weary. 2000. Reducing pain after dehorning in dairy calves. J. Dairy Sci. 83:2037-2041.

Graf, B., and M. Senn. 1999. Behavioural and physiological responses of calves to dehorning by heat cauterization with or without local anaesthesia. Appl. Anim. Behav. Sci. 62:153-171.

Grøndahl-Nielsen, C., H. B. Simonsen, J. Damkjer Lund, and M. Hesselholt. 1999. Behavioural, endocrine and cardiac responses in young calves undergoing dehorning without and with use of sedation and analgesia. Vet. J. 158:14-20.

Hagen, K., J. Langbein, C. Schmied, D. Lexer, and S. Waiblinger. 2005. Heart rate variability in dairy cows-influences of breed and milking system. Physiol. Behav. 85:195-204

Malik, M., and A. J. Camm. 1995. Heart Rate Variability. Futura Publishing Company, Armonk, NY.

Marchant-Forde, R. M., D. J. Marlin, and J. N. Marchant-Forde. 2004 Validation of a cardiac monitor for measuring heart rate variability in adult female pigs: Accuracy, artefacts and editing. Physiol. Behav. 80:449-458.

McMeekan, C., K. J. Stafford, D. J. Mellor, R. A. Bruce, R. N. Ward, and N. Gregory. 1999. Effects of local anaesthetic and a nonsteroidal anti-inflammatory analgesic on the behavioural response of calves to dehorning. N. Z. Vet. J. 74:92-96.

Mohr, E., J. Langbein, and G. Nurnberg. 2002. Heart rate variability: A noninvasive approach to measure stress in calves and cows. Physiol. Behav. 75:251-259.

Morisse, J. P., J. P. Cotte, and D. Huonnic. 1995. Effect of dehorning on behaviour and plasma cortisol responses in young calves. Appl. Anim. Behav. Sci. 43:239-247.

New Zealand Veterinary Association (NZVA). 2000. Standard Operating Procedure for the Process of Humane Disbudding of Calves. Prepared by National Quality Veterinary Services, Wellington, New Zealand.

Niskanen, J. P., M. P. Tarvainen, P. O. Ranta-Aho, and P. A. Karjalainen. 2004. Software for advanced HRV analysis. Comput. Methods Programs Biomed. 76:73-81.

Petrie, N. J., D. J. Mellor, K. J. Stafford, R. A. Bruce, and R. N. Ward. 1996. Cortisol responses of calves to two methods of disbudding used with or without local anaesthetic. N. Z. Vet. J. 44:9-14.

Schwartzkopf-Genswein, K. S., M. E. Booth-McLean, T. A. McAllister, and G. J. Mears. 2005. Physiological and behavioural changes in Holstein calves during and after dehorning or castration. Can. J. Anim. Sci. 85:131-138.

Sleigh, J. W., and J. D. Henderson. 1995. Heart-rate-variability and preoperative anxiety. Acta Anaesthesiol. Scand. 39:1059-1061.

Stafford, K. J., and D. J. Mellor. 2005. Dehorning and disbudding distress and its alleviation in calves. Vet. J. 169:337-349.

Stewart, M. 2008. Non-invasive measurement of stress and pain in cattle using infrared thermography. PhD thesis. Massey University, Palmerston North, New Zealand.

Stewart, M., K. J. Stafford, S. K. Dowling, A. L. Schaefer, and J. R. Webster. 2008. Eye temperature and heart rate variability of calves dehorned with or without local anaesthetic. Physiol. Behav. 93:789-797.

Task Force of the European Society of Cardiology and the North American Society of Pacing and Electrophysiology. 1996. Heart rate variability: Standards of measurement, physiological interpretation and clinical use. Circulation 93:1043-1065. PubMed

von Borell, E., J. Langbein, G. Despres, S. Hansen, C. Leterrier, J. Marchant-Forde, R. Marchant-Forde, M. Minero, E. Mohr, A. Prunier, D. Valance, and I. Veissier. 2007. Heart rate variability as a measure of autonomic regulation of cardiac activity for assessing stress and welfare in farm animals - A review. Physiol. Behav. 92:293-316.

Weaver, A. D., G. St. Jean, and A. Steiner. 2005. Bovine Surgery and Lameness. Blackwell Publishing Ltd., Oxford, UK. 